\title{
Entrevista
}

\section{Ensino-aprendizagem de línguas: um outro olhar}

\section{Uma entrevista com Patrick Anderson}

\begin{abstract}
Patrick Anderson
Professor da Université de Franche-Comté, Besançon, França; membro do Laboratoire ELLIADD. Autor do livro La didactique des langues étrangères à l'épreuve du sujet (1999) e de outros artigos que contemplam a temáticas: sujeito desejante, ensino e aprendizagem de línguas, enunciação. Ministrou um curso para os alunos do Programa de Pós-graduação em Estudos Linguísticos (PPGEL-ILEEL/UFU), juntamente com a Profa. Dra. Carla Tavares (março-junho de 2012), abordando exatamente a referida temática.
\end{abstract}

\section{Entrevistadores}

Carla Nunes Vieira Tavares*

Isabel Silva Alves Quintino

João de Deus Leite ${ }^{+}$

E: Gostaríamos de iniciar nossa conversa, perguntando-lhe: Como foi seu encontro com a docência em termos de sua decisão profissional por ela?

\footnotetext{
* Professora Doutora no Instituto de Letras e Linguística (ILEEL), da Universidade Federal de Uberlândia (UFU), de Minas Gerais.

Discente do Programa de Pós-graduação em Estudos Linguísticos (PPGEL), do Curso de Mestrado, do Instituto de Letras em Linguística (ILEEL), da Universidade Federal de Uberlândia (UFU), de Minas Gerais.

+ Discente do Programa de Pós-graduação em Estudos Linguísticos (PPGEL), do Curso de Doutorado, do Instituto de Letras em Linguística (ILEEL), da Universidade Federal de Uberlândia (UFU), de Minas Gerais.
} 
P.A: Primeiramente, houve meu interesse durante os meus anos primários. Depois no ensino médio, por um lado, por causa da História e das obras literárias, e ainda por cima, gostava muito de gramática. Tive a chance de ter verdadeiros professores que me fizeram amar a literatura e a língua. Eu vim para a linguística por acaso, depois do baccalauréat ${ }^{1}$ sessão de filosofia, (isso existia na época!). Escolhi fazer um pouco de inglês e espanhol paralelamente aos estudos de direito. O inglês era um vínculo com a minha família. Meu avô era escocês e meus pais sempre me enviavam nas férias para a casa dos meus primos na Grã-Bretanha. Sobretudo, eu não queria falar inglês como os franceses falam. Eu regredi muito desde então, porque raras são as ocasiões para praticar.

Procurei na época algo que me permitisse viajar e tornar-me advogado de direito internacional me parecia conveniente. Evidentemente, não fazia ideia do que isso era na realidade. Tinha uma ideia muito idealizada: jato, garotas, carro esportivo, etc. No cinema era James Bond! Muito rápido, percebi que o direito não me interessava. Encontrava, no fundo do anfiteatro, outros que, como eu, estavam pouco interessados, e partíamos para a cinemacoteca e para os cinemas do Quartier Latin. Naquele momento, identifiquei-me com uma cultura cinematográfica. Do Direito, só guardei a lembrança da narrativa do processo do fabricante de queijos "La Vache Qui Rit» contra o fabricante da marca "La Vache Sérieuse".

O período era marcado por uma grande agitação intelectual. Eram os anos que precediam e que seguiriam 1968. Em uma noite, por ocasião de uma reunião na Universidade de Paris III, perguntaram-nos se havia estudantes interessados em um curso de Linguística Geral. Fui ao curso e mergulhei na área. Tive a chance de ter aula com grandes nomes da disciplina: Ruwet, Gross, Chevalier, Shane, (eles eram convidados de Chomsky); em literatura: Mitterand, Neef, Kuentz, Duchet, Cixoux, Bellemin-Noël. Paralelamente, eu frequentava a Aliança Francesa, onde havia o teatro e garotas... Propuseram-me trabalhar em uma nova escola de línguas que acolhia a classe social alta dos países estrangeiros: embaixadores, industriais ricos, filhinhos e filhinhas de papai, etc. No meio dessa fauna, havia também pessoas interessantes, profissionais

\footnotetext{
${ }^{1}$ N.T. Trata-se do exame de conclusão do Lycée no contexto francês; no Brasil, seria o grau de ensino equivalente ao ensino médio.
} 
enviados por seus países (médicos, arquitetos, engenheiros) e foi dessa forma que criei minha prática do ensino do francês para estrangeiros.

Em seguida, nos meus estudos, avancei cada vez mais em direção ao campo da interrogação sobre a aprendizagem de uma língua outra. Em Paris, ensinei na Escola Nacional de Administração, que forma os tecnocratas, mas à noite trabalhava no setor de alfabetização, no subúrbio norte de Paris. O contraste era gritante! Os tecnocratas falavam dos imigrantes sem ter visto nenhum de perto! Depois, trabalhando nos Estados Unidos, na Universidade do Kansas (KU), em Lawrence, tinha a ideia ingênua de que os americanos se interessavam pela linguística (grande ilusão - não mais do que em qualquer lugar; sem dúvida havia interesse no MIT, mas não lá no interior do Kansas! Seria preciso estudar agronomia!).

Retornando à França, ensinei na Universidade de Paris III, depois tive um cargo em Besançon, no Centro de Linguística Aplicada (CLA), onde fiquei vinte anos (antes que o instituto se tornasse um supermercado!). Em seguida, concursei-me Mestre de Conferências na Universidade de Haute Alsace e, mais tarde, tornei-me Professeur des Universités $^{2}$, em Besançon. Essas foram as minhas experiências como professor que me conduziram em direção ao meu doutorado.

Como havia iniciado um processo de análise, na corrente psicanalítica, os efeitos do tratamento fizeram com que meu interesse de pesquisa fosse modificado. O que guardo de tudo isso é que tive uma chance enorme, pois, na época dos meus estudos universitários, havia uma liberdade que não existe mais, pelo menos se considerado o que vejo em Besançon. O que quero dizer é que eu era estudante em linguística geral, mas que tinha a possibilidade de ir escutar Deleuze, no departamento de filosofia; ou Cixoux, que falava de Joyce, e ela mesma era próxima de Derrida. Tudo estava aberto e até me recordo de fazer, por puro prazer, um curso sobre Pirandello, no departamento de italiano. Essa leveza que correspondia à tradição universitária europeia, nós a perdemos.

E: Conte-nos um pouco sobre sua experiência com o ensino e aprendizagem de língua(s), tendo em vista exatamente o fato de o senhor dar aulas de sua língua dita

\footnotetext{
${ }^{2}$ N.T. O cargo de Maître de Conférences, na França, equivale ao posto de professor universitário no Brasil, restringindo a área de atuação do professor à graduação; enquanto o Professeur des Universités atua também na pós-graduação e na direção de pesquisas.
} 
materna, no caso a língua francesa, como se ela tivesse o estatuto de estrangeira. Isso porque o senhor ensinava a língua francesa para pessoas que não possuem com ela um vínculo de língua materna.

P.A: Ensinar sua língua para estrangeiros acaba por suscitar questões pouco comuns e, nesse sentido, faz alguém descobrir sua própria língua. No início, jovem professor, deixava-me cair em armadilhas na medida em que os estrangeiros faziam perguntas para as quais não havia resposta, porque a única resposta possível era: é assim, porque é! As perguntas eram do tipo: por que esta palavra é feminina? No século XIX uma escola de gramáticos se debruçara sobre o absurdo e procurava a feminilidade na cadeira e a masculinidade na poltrona ${ }^{3}$. Vemos de resto que os estrangeiros perguntavam as questões não para ter uma resposta, mas para se certificarem dela e se tranquilizarem. Devido a esses deslizes da juventude, quebrei a cabeça, por vezes, com coisas insignificantes, mas também aprendi muito com meus próprios erros. Tive a chance de encontrar algumas pessoas de todas as partes do mundo e isso é apaixonante. Por exemplo, guardas florestais de Ceausescu, guias do Nepal, (pilotos de helicóptero no Himalaia), pilotos egípcios de jatos Migs, americanos influentes do movimento «Black Panthers », indianos brâmanes, papuásios (da Nova Guiné), antropólogos mexicanos, cineastas chilenos, etc. Conversava de inúmeras coisas com essas pessoas durante a aula, e a última coisa que eu as ensinava era dizer: passe-me o sal!

E: Em alguns artigos, o senhor problematizou fortemente o cerne do quadro dominante da didática de línguas estrangeiras (DLE), mostrando-nos em que a hipótese do inconsciente freudo-lacaniano fundamentaria a visada de sua leitura problematizadora. De seu ponto de vista, haveria desdobramentos da hipótese do inconsciente na constituição epistemológica da DLE?

P.A: A DLE, nas suas opções dominantes, é totalmente subserviente, por um lado, ao neoliberalismo econômico, o que se traduz no utilitarismo que marca a dimensão da língua; e, por outro, aos modismos que conduzem a formas de

\footnotetext{
${ }^{3}$ N.T. Em francês, a palavra chaise equivale à cadeira, em português, e é feminina, mas palavra fauteuil é masculina e equivale à poltrona em português.
} 
inconsistência epistemológica. Por exemplo, adotamos, sem discussão, opções metodológicas sem nos perguntar de onde elas provêm, à qual campo do conhecimento elas fazem parte. Questionei a abordagem comunicativa e mostrei que não há um ponto de fundação nessa teorização; sua validação só foi dada com o passar do tempo e foi por isso que a caracterizei como objeto inatingível! Por exemplo, ao observar os prefácios dos livros de francês como língua estrangeira, verifica-se que geralmente postulam objetivos comunicativos e, por vezes, superficialmente, citam como referência Austin e Searle, mas jamais Wittgenstein. Ora, só podemos compreender a elaboração de Austin se partirmos do que o precedeu. A coisa é elaborada como se houvesse caído diretamente do céu. Proponho o contrário, ou seja, precisamos sacudir um pouco nossas cabeças para devolver um lugar ao sujeito que aprende. Dizendo melhor, é necessário refletir sobre o que pode significar ser um sujeito cindido pela linguagem, ou, em outras palavras, um sujeito trabalhado pelo inconsciente. Em meu livro ${ }^{4}$, postulei a seguinte questão: O que fazemos da linguística? O que fazemos do saber desse campo no ensino de línguas? A análise do tema me conduziu a constatar que não fizemos grandes coisas nem com esse saber nem com o fato de aprender ou com o sujeito. Desde essa constatação o cenário é ainda mais sombrio! Aprender hoje seria essencialmente: ser capaz de..., realizar uma tarefa... Ora, a filosofia nos ensina que não se trata disso, evidentemente! O aluno é um ersatz $z^{5}$ de sujeito. A didática de línguas, com suas opções dominantes, crê ter inventado a roda! Não se trata de remendar algo que já nasceu esburacado, mas de tentar dar um pouco de consistência a isso. Trata-se de um problema bem mais geral, já que toca a questão do desaparecimento do saber hoje em nossa póspós modernidade, com consequências para a questão que não cessa de ser indagada no decorrer dos séculos: o que é ser professor? O que é ensinar? O que é aprender?

E: Em suas aulas, o senhor enfatizou a ideia de que "falar uma língua" não se reduziria jamais ao "saber gramatical" que se pode ter dela, e vice-versa. Para tanto, o senhor mobilizou a relação entre domínio semiótico e domínio semântico, segundo

\footnotetext{
${ }^{4}$ N.T. ANDERSON, Patrick. La didactique des langues étrangères à l'épreuve du sujet. Besançon: Press Universitaires Franc-Comtoises, 1999.

${ }^{5}$ N.T. Ersatz é uma palavra que vem do alemão e designa um substituto de algo, mas com qualidade inferior; como se estivesse na falta de algo melhor.
} 
distinção produzida por Benveniste (1969), buscando dimensionar a necessidade de se colocar em jogo, na aprendizagem de uma língua, a instância da fala. Em que essa instância se diferencia do que a DLE entende por oralidade? Em sendo assim, de sua perspectiva, por que a aposta nessa instância pode se mostrar relevante e pertinente na aprendizagem de uma língua?

P.A: Antes de tudo me parece que a dimensão importante é aquela do prazer. Há um prazer na oralização, na emissão dos sons, na produção dos fonemas (isso é muito presente nas crianças). Por outro lado, sabemos que nos voltamos para aquilo que nos agrada e aprendemos mais facilmente com isso. $\mathrm{O}$ vínculo que nos inscreve como seres falantes nos especifica, por um lado, como homo sapiens, mas também nos liga à classe dos mamíferos superiores, estabelecendo, portanto, uma ligação intrínseca entre a dimensão natural e a cultural. Assim, parece-me que essa dimensão que funda ao mesmo tempo uma certa relação com a oralidade é deixada de lado. Quero dizer que os foneticistas nos falam da correção dos fonemas, da intensidade mensurável, etc. Mas não tocam em aspectos concernentes ao silêncio, à voz, ao sopro, à respiração. Quando falamos, falamos com todo o nosso corpo. Certamente há muitas coisas sobre isso no campo das Artes Cênicas. Por outro lado, a onipresença da gramática, o superinvestimento devotado à significação em seu aspecto puramente semântico, a insistência relacionada à dimensão pragmática suprimem um outro tipo de relação. A obra de Mizubayashi ${ }^{6}$ é importante porque o autor nos mostra que é possível entrar em uma língua estrangeira pela musicalidade da língua. Quando Benveniste separa semiótico e semântico, ele nos diz que a dimensão fundamental é o semântico. A questão a ser colocada é por que continuamos vinculados à dimensão semiótica - sem dúvida pela tradição.

E: De seu ponto de vista teórico, o que significa dizer que a inscrição do sujeito em uma língua estaria para a ordem do apropriar-se da língua do outro? Haveria aí uma relação com a enunciação, conforme entendida por Benveniste (1970)?

${ }^{6}$ N.T. O autor se refere à obra de MIZUBAYASHI, A. Une langue venue d'ailleurs. Paris, FR: Gallimard, 2011. 
P.A: Apropriar-se da língua do outro? Não! Porque não é possível dizer que alguém possui uma língua. Pelo contrário, poderíamos dizer que a língua possui o sujeito. É comum ouvir: ah, ele fala bem; ele domina bem a língua. Mas se diz isso de um estrangeiro, raramente de um locutor nativo, sob o risco de ser pedante ou presunçoso. Quer dizer, há sempre o sentido de algo não concluído, o sentido de que a relação com a língua não está jamais terminada. Portanto, tudo depende da posição subjetiva do sujeito: como ele investirá subjetivamente a língua do outro? O que quer dizer para ele falar essa língua? O que ele espera inconscientemente? Percebe-se, inclusive, que a questão ultrapassa a aquisição e a aprendizagem, porque ela toca a identidade do sujeito. Assim, se pensamos que uma língua deve ser falada, isso nos leva a considerar que alguém que aprende uma língua precisa resolver o seguinte problema: ele deverá construir para si uma outra enunciação, pois já está inscrito em uma. O que nos diz Benveniste é muito simples. A língua só existe no momento em que é ativada, quer dizer, quando um locutor se vale do sistema e o atualiza. A questão problemática é se perguntar porque foi preciso tanto tempo para se chegar a essa conclusão e porque se continua a produzir livros de gramática que não levam em conta a enunciação.

E: Para efeitos de formação do professor de língua(s) em geral, haveria necessariamente uma relação de implicação entre conhecer as teorias de linguagens e a prática do professor, segundo seu ponto de vista?

P.A: Seria possível imaginar um mecânico que não conhece minimamente algo de mecânica de automóveis? É certo que existem bons e maus profissionais, mas eles precisam se confrontar com a materialidade de motos. É bem difícil imaginar um médico que não conheça um mínimo de anatomia. Quanto aos advogados, já não é tão difícil, porque há muitos impostores que se fazem passar por advogados diante de um tribunal e, às vezes, são bem-sucedidos na farsa. Por isso, parece-me necessário indagar em que medida as teorias são necessárias e suficientes para abordar a questão do ensino/aprendizagem de uma língua. A resposta é que teoria e prática estão intrinsecamente relacionadas, porque o que desencadeará uma outra forma de saber é a prova da realidade pedagógica; porém, diante das dificuldades práticas, a base virá dos fundamentos teóricos. 
A indagação geral colocada pelos professores em formação é: O que fazer? Como fazer? Dê-nos um guia. Queremos um bem fazer que dê certo (e é claro que ninguém quer meter os pés pelas mãos). Ora, se encaramos a questão sob a perspectiva da prática, veremos que jamais haverá um "bem-fazer". O que permitirá a articulação das questões de modo a encontrar uma saída possível é a base das teorias que foram digeridas, no sentido de que elas devem constituir-nos enquanto professores.

A questão permanece difícil, porque é possível ter o conhecimento e ser incapaz de transmiti-lo. O contrário também pode acontecer: no lugar da transmissão, ocorrer a sedução pelo dizer e pelo carisma e construir-se uma ilusão de saber. Ensinar ainda significa ser capaz de permitir ao outro confrontar seu próprio vazio, o que não implica dizer ao professor que ele deva se colocar em posição de detentor do saber, mas permitir a ruptura que comportará o despertar de questões que, diferentemente, não existiriam. Esse processo não equivale de modo algum a propiciar um ensino prazeroso. De modo que eu diria: desconfiemos dos professores que propagam: "Meus alunos, meus estudantes...", e das pessoas que insistem que querem o nosso bem. Mas isso é outra questão.

Uma última observação subsidiária, não central, mas que notei em minhas viagens aqui, durante as apresentações de trabalho e comunicações em eventos (e que ocorre também com na França). Fiquei impressionado com algo que me pareceu como um jogo da batata quente: eu cito você, você me cita e ficamos entre nós. É o esplendor da academia universitária. Gostaria de dizer que os textos fundadores não são tão numerosos assim; por isso, porque não ir até eles? Ainda há muito a descobrir. Foucault ou Derrida (por exemplo) só serão interessantes na medida em que os fizermos ressoar em nossas preocupações. Sem esse trabalho, parece que se estabelece uma espécie de veneração, um culto aos ancestrais, com a construção de monumentos funerários e tudo o mais. Só falta acrescentar o formol...

Outono, 2012

Brasil/Uberlândia (MG) 